\title{
WAS ARISTOTLE A VIRTUE ARGUMENTATION THEORIST?
}

\author{
ANDREW ABERDEIN*
}

Virtue theories of argumentation (VTA) emphasize the roles arguers play in the conduct and evaluation of arguments, and lay particular stress on arguers' acquired dispositions of character, that is, virtues and vices. The inspiration for VTA lies in virtue epistemology and virtue ethics, the latter being a modern revival of Aristotle's ethics. Aristotle is also, of course, the father of Western logic and argumentation. This paper asks to what degree Aristotle may thereby be claimed as a forefather by VTA.

A tempting way of addressing this question might be to say that since Aristotle was a virtue theorist and an argumentation theorist, surely he must have been a virtue argumentation theorist! But not only is this an invalid argument, it is not even clear that the premisses are true. There is no word corresponding exactly to

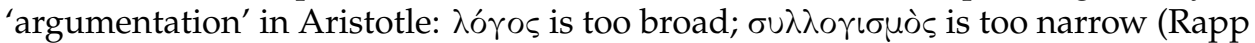
and Wagner. 2013, 15). So, although Aristotle wrote about many aspects of what we now describe as argumentation, we cannot infer that he conceptualized these aspects as comprising a single field. What's more, even the familiar perception of Aristotle as paradigm virtue ethicist is open to challenge (Santas. 1997). So, taken as a purely historical question, the answer to my title must be no. However, my project is an anachronistic one: I hope to demonstrate that a careful reading of some of Aristotle's work on argumentation is of enduring relevance to VTA.

The roots of VTA lie in much grander projects, which I survey briefly in $\sqrt[8]{1} \frac{8}{2}$ turns to what Aristotle has to say about the relationship of character to argument, and how that may be of use to VTA. $\$ 3$ addresses one of those things that holds particular promise for VTA: the status of the phronimos as ideal arguer.

\section{What ARE VIRTUE THEORIES OF ARGUMENTATION?}

I have made a point of referring to virtue theories of argumentation in the plural, since, despite its youth and comparatively small scale, the programme has been undertaken in several distinct ways. That heterogeneity owes something to the range of inspirations behind VTA, three of which I survey below.

1.1. Virtue epistemology. One big question confronting any virtue theorist is "What counts as a virtue?". In virtue epistemology, the standard way of splitting up the possible answers is between reliabilist and responsibilist virtues (Axtell. 1997). The former are most often associated with Ernest Sosa, who includes as virtues many things which don't much look like virtues, such as the faculty of sight (Sosa, 1991). Reliabilist virtues are involuntary, but reliable, knowledgeproducing processes. They stand in contrast to responsibilist virtues, notably proposed by Linda Zagzebski (1996). These virtues, such as open-mindedness,

* School of Arts \& Communication, Florida Institute of Technology, Melbourne FL.

Date: November 30, 2019. 
look more like ethical virtues. They are voluntarily exercised aspects of character that require conscious effort of will. Many virtue epistemologists incorporate both types of virtue into a mixed approach (for example, Battaly, 2008). When we turn to argumentation, the roll call of virtues may look much the same. Maybe there are argumentation-specific virtues that need to be added. Conversely, some virtues lack obvious relevance to argumentation, so may be downplayed. Or perhaps we will need to specifically fine-tune the virtues for argumentation: openmindedness in arguing and open-mindedness in knowing are not necessarily the same thing, for example (Cohen, 2009, 57). But VTA need not depend on novel virtues for novelty. And the disputes over precisely which virtues to include seem to closely track their counterparts in virtue epistemology.

The other main dimension distinguishing virtue theories concerns the choice of project. For epistemology, this is a distinction between 'classical' projects addressing core questions such as "What is knowledge?"; and projects addressing more neglected questions, such as "What is the value of knowledge?". Some virtue epistemologists just focus on the former, by trying to find a virtue response to the standard questions; some just look at the latter, trying to see what virtue epistemology can say about the neglected questions; some people apply the virtue apparatus to both sorts of project. The classical project of argumentation does not ask "What is the nature of knowledge?", it asks "What distinguishes good argument from bad argument?". But there are neglected questions in argumentation theory too: questions about the value of argumentation, and what makes an argument truly satisfying; about how arguments contribute to human flourishing, and whether we need a more eudaimonistic conception of argument. Once again, one can pursue both projects, as I have tried to do in my own contributions to VTA. Many other people who have some allegiance with VTA focus exclusively on the neglected questions. That is an understandable choice, since it is where the most obvious dividends lie, but I maintain that a more ambitious project is defensible (for a taxonomy of such projects, see Paglieri. 2015. 77).

Returning to the question of which virtues to follow, let us review some core virtues of virtue epistemology to see if we can appropriate them for argumentation. Heather Battaly lists as "paradigm" reliabilist virtues "sense perception, induction, deduction, and memory" (Battaly, 2008, 644). Induction and deduction have an obvious relevance to argumentation. Indeed, they lend themselves to what one might call 'easy road' VTA: accept these as virtues, and any account of argument becomes a virtue theory, but in the trivial sense that if deductive and inductive reasoning are virtues then every theory of reasoning is a virtue theory. This may be an unilluminating approach to VTA (but for further discussion, see Aberdein, 2018). It seems that any sufficiently interesting VTA will not be strictly reliabilist, but will also recognize some responsibilist virtues. Indeed, Zagzebski's Virtues of the Mind, although a work in epistemology, not argumentation theory, proposes several virtues that look like virtues of argument. She actually includes "fairness in evaluating the arguments of others", while virtues such as "intellectual humility" are certainly important to argumentation; likewise "thinking of coherent explanations" and "being able to recognize reliable authority" (Zagzebski, 1996. 114). Such virtues could contribute to an understanding of the value of argument. Perhaps they can also recapture the idea of cogency, of what makes arguments good ones. One way such a project might get off the ground would be 
to define a cogent argument as an argument that a virtuous arguer would make in relevant circumstances and then cash out what a virtuous arguer looks like in terms of the virtues they would need.

1.2. Critical Thinking Dispositions. If one root of VTA lies in contemporary epistemology, another lies in education. Some of the earliest treatments of critical thinking in educational theory framed it solely in terms of skills. More sophisticated accounts argued that skills should be supplemented with dispositions: tendencies or inclinations to actually use these skills in a way that fosters successful critical thinking. In the hands of such pioneers as Robert Ennis and Peter Facione, this work led to detailed inventories of critical thinking dispositions and instruments whereby they could be assessed (Ennis, 1996, Facione, 2000). The debate whether or not mastery of critical thinking involves the inculcation of dispositions was won by the advocates of dispositions: "Virtually all the major theorists of critical thinking ... make dispositions central to their accounts" (Bailin and Siegel, 2003. 193). This early research was conducted significantly in advance of the emergence of VTA, and seldom drew a direct connection to the use of virtues in other nearby fields, such as epistemology. Nonetheless, the dispositions in question look a lot like virtues. After all, we follow Aristotle in defining a virtue as a disposition (Aristotle, 1976, 1106b35), and these specific dispositions have quite virtue-like qualities:

The primary disposition consists in valuing good reasoning and being disposed to seek reasons, to assess them, and to govern beliefs and actions on the basis of such assessment. In addition, most theorists outline a subset of dispositions that are also necessary for critical thinking, including open-mindedness, fairmindedness, independent-mindedness, an inquiring attitude, and respect for others in group inquiry and deliberation (Bailin and Siegel, 2003, 183).

Here's a more extensive list from Robert Ennis, the doyen of critical thinking literature:

(1) Care that their beliefs be true, and that their decisions be justified; that is, care to "get it right" to the extent possible, or at least care to do the best they can. This includes the interrelated dispositions to do the following:

(a) Seek alternatives (hypotheses, explanations, conclusions, plans, sources), and be open to them;

(b) Endorse a position to the extent that, but only to the extent that, it is justified by the information that is available;

(c) Be well-informed; and

(d) Seriously consider points of view other than their own.

(2) Represent a position honestly and clearly (theirs as well as others'). This includes the dispositions to do the following:

(a) Be clear about the intended meaning of what is said, written, or otherwise communicated, seeking as much precision as the situation requires;

(b) Determine, and maintain focus on, the conclusion or question;

(c) Seek and offer reasons;

(d) Take into account the total situation; and

(e) Be reflectively aware of their own basic beliefs. 
(3) Care about the dignity and worth of every person. This includes the dispositions to:

(a) Discover and listen to others' view and reasons;

(b) Take into account others' feelings and level of understanding, avoiding intimidating or confusing others with their critical thinking prowess; and

(c) Be concerned about others' welfare (Ennis, 1996, 171)

Much of this looks as much like ethics as epistemology. But so it should: argumentation straddles the two. Argumentation obviously has connections to epistemology, in so far as it is a source of justification for our beliefs; but it also, since it involves interacting with other people, raises questions about how to do that in the best way. So the interpersonal nature of argumentation requires ethical as well as epistemic virtues.

1.3. Virtues of argument. VTA emerged in the 2000s, with its own sets of virtues. Daniel Cohen, probably the best-known advocate of VTA, proposes four basic virtues: willingness to engage in serious argumentation; willingness to listen to others; willingness to modify one's own position; willingness to question the obvious (Cohen, 2005, 64). Cohen's account is Aristotelian at least in the sense that his virtues are all situated as means between vices of deficiency or excess. This yields a rogue's gallery of bad arguers, some of them quite recognizable types: for example, the Concessionaire concedes things too readily; the Deaf Dogmatist never listens to anyone; the Eager Believer believes whatever they're told; and the Unassuring Assurer assures you of things in a way that makes you doubt what you otherwise wouldn't (for the full picture, see Aberdein, 2016. 416).

My own list of virtues was directly inspired by Cohen's:

(1) willingness to engage in argumentation

(a) being communicative

(b) faith in reason

(c) intellectual courage

(i) sense of duty

(2) willingness to listen to others

(a) intellectual empathy

(i) insight into persons

(ii) insight into problems

(iii) insight into theories

(b) fairmindedness

(i) justice

(ii) fairness in evaluating the arguments of others

(iii) open-mindedness in collecting and appraising evidence

(c) recognition of reliable authority

(d) recognition of salient facts

(i) sensitivity to detail

(3) willingness to modify one's own position
(a) common sense
(b) intellectual candour
(c) intellectual humility
(d) intellectual integrity 
(i) honour

(ii) responsibility

(iii) sincerity

(4) willingness to question the obvious

(a) appropriate respect for public opinion

(b) autonomy

(c) intellectual perseverance

(i) diligence

(ii) care

(iii) thoroughness (Aberdein, 2010, 175).

(1), (2), (3), and (4) are Cohen's virtues, but their subdivisions are from other sources (in particular, Zagzebski, 1996, 114). Elsewhere, I have also presented these virtues as means between vices (Aberdein, 2016, 416). Despite the hierarchical structure of this list, I do not mean to imply that any such taxonomy of virtues could ever be definitive. But, although many of the details of this list are open to dispute, it at least indicates how closely intertwined VTA can be with more traditional accounts of virtue.

\section{What does Aristotle say about Character AND ARgUment?}

In exploring Aristotle's potential as a precursor of VTA, two broad strategies present themselves. One option would be to analyse Aristotle's own argumentational practice for traces of an implicit virtue theory. I shall not take that tack in this paper (but, for an example of how this might work, applied to Plato, see Aikin and Anderson, 2006). The other prospect is to examine what Aristotle explicitly asserts about argumentation. This significantly narrows the focus of the enquiry: Aristotle has a lot to say about virtue and character, but little of it is in the context of logic. Indeed, I am aware of no direct virtue references in any of his works on formal logic (the Categories, On Interpretation, or the Prior Analytics). However, the Topics and the Rhetoric, where he addresses informal logic, are richer sources.

2.1. Topics VIII. The Topics is an early work and focussed on a somewhat artificial task: success in competitive debate exercises intended for students. This may raise the concern that any insights gleaned from it will be of narrow application. However, as Sara Rubinelli remarks, "as a result of designing this method, which basically comprises the rules of a game, [Aristotle] created the first treatise on argumentation theory of the Western world!" (Rubinelli. 2009. 7). Catarina Dutilh Novaes goes further, arguing that rethinking the normativity of logic in explicitly dialogical terms, thereby essentially returning to the perspective of the Topics, provides a more attractive account of the relationship of logic to reasoning than the more familiar monological picture (Dutilh Novaes, 2015. 596).

There is not a great deal of discussion of character or virtue in the Topics, but there are some significant passages. I shall focus on four.

With regard to the giving of answers, we must first define what is the business of a good answerer, as of a good questioner. The business of the questioner is so to develop the argument as to make the answerer utter the most extravagant paradoxes that 
necessarily follow because of his position: while that of the answerer is to make it appear that it is not he who is responsible for the absurdity or paradox, but only his position: for one may, perhaps, distinguish between the mistake of taking up a wrong position to start with, and that of not maintaining it properly, when once taken up (Aristotle, 1984, 159a16-24).

Here Aristotle addresses the contrasting strengths of the two parties to the sort of semi-formal debate he is discussing: the questioner and answerer, or proponent and respondent. Although he does not invoke virtue directly here, he does discuss what is required to play each role well. He also draws a distinction between the arguer and the position defended by the arguer; something characteristically overlooked in much argumentation theory, but of greater salience in VTA. This distinction is also key to the following passage:

He [the answerer] should beware of maintaining an implausible hypothesis ... which a bad character would choose, and which [is] opposed to men's wishes (e.g. that pleasure is the good, and that to do injustice is better than to suffer it). For people then hate him, supposing him to maintain them not for the sake of argument but because he really thinks them (Aristotle, 1984, 16ob1723).

On the one hand, this passage stresses the importance to the arguer of not being thought vicious, or in other words, of (being seen as) arguing as a virtuous arguer would argue, a core principle of VTA, as we have seen. On the other hand, the emphasis is firmly on the vicious aspects of the hypothesis, not the argument by which that hypothesis is defended, so this is not a virtuistic analysis of argument as such. Moreover, it is presented in instrumental terms: implausible hypotheses are to be avoided for fear of reputational damage, not because they are inherently wrong. However, the concern with reputation is consistent with its playing a role in argument evaluation. More specifically, it raises a question that has recently attracted interest from a VTA perspective: can a virtuous arguer be a devil's advocate? (Cohen and Stevens, 2019; see also Callard, 2019).

There is more in Topics VIII about bad argumentational practice, some of it perhaps inveterate, and thereby rising to the level of vice:

Accordingly it sometimes becomes necessary to attack the speaker and not his thesis, when the answerer lies in wait for the points that are contrary to the questioner and becomes abusive as well: when people lose their tempers in this way, their argument becomes contentious, not dialectical (Aristotle, 1984, 161a21-23).

Focussing the attack on the speaker indicates that Aristotle sees ad hominem tactics as at least sometimes justified. This is a prerequisite for VTA, since appraising arguments in terms of the arguers' characters cannot get off the ground if all such appraisal is deemed fallacious (see Aberdein. 2014, 89, in which I argue that ad hominem arguments are legitimate if and only if they address specifically argumentational character flaws).

Other passages suggest more strongly that some arguers are more prone to bad practice than others, again reinforcing an analysis of argument in terms of vices: 
Do not argue with every one, nor practise upon the man in the street; for there are some people with whom any argument is bound to degenerate. For against any one who is ready to try all means in order to seem not to be beaten, it is indeed fair to try all means of bringing about one's conclusion; but it is not good form [ $\varepsilon \dot{v} \sigma \chi \eta \mu o v]$. Therefore the best rule is, not lightly to engage with the man in the street, or bad argument is sure to result. For you see how in practising together people cannot refrain from contentious argument (Aristotle, 1984, 164b7-15).

As Robin Smith paraphrases, "The problem with engaging in this kind of argument is that it encourages bad habits of argumentation" (Smith, 1997, 163). This concern to avoid bad argument, even at the cost of avoiding arguing altogether, foreshadows an important theme in VTA of attending closely to the value of arguments, and more specifically contradicts the Socratic commonplace that one should never give up on arguing (see Campolo, 2019. 721; cf. Aberdein, 2019).

2.2. Rhetoric I. The Rhetoric is a richer source for insights relevant to VTA than the Topics. I shall concentrate on two passages, one from I.2, one from II.1. I should reiterate that I am quarrying Aristotle, not proposing a definitive reading. Indeed, some scholars suggest that the Rhetoric exhibits traces of more than one stage of Aristotle's thought, and therefore cannot sustain such a reading (let alone a synoptic reading with Aristotle's other virtue theoretic texts) (Fortenbaugh, 1992,232 ff.).

Of those proofs that are furnished through the speech there are three kinds. Some reside in the character of the speaker, some in a certain disposition of the audience and some in the speech itself, through its demonstrating or seeming to demonstrate. Proofs from character are produced, whenever the speech is given in such a way as to render the speaker worthy of credence-we more readily and sooner believe reasonable men on all matters in general and absolutely on questions where precision is impossible and two views can be maintained. But this effect too must come about in the course of the speech, not from the speaker's being believed in advance to be of a certain character. Unlike some experts, we do not exclude the speaker's reasonable image from the art as contributing nothing to persuasiveness. On the contrary, character contains almost the strongest proof of all, so to speak. (Aristotle, 1991, 1356a)

This passage says several things encouraging for VTA. Firstly, the "character of the speaker" and the "disposition of the audience" have been made equal partners with what is actually said. Secondly, the particular relevance of character to "questions where precision is impossible and two views can be maintained" indicates we are concerned with informal reasoning, and more narrowly, pro and con arguments, or "conductive argumentation" (Blair and Johnson, 2011). VTA are likewise aimed at informal argumentation. And, at the very least, this passage shows Aristotle taking ethotic argument very seriously: "almost the strongest proof of all". As Gregory Beabout comments on this passage, "In other words, the pursuit of mastery in the art of rhetoric involves practicing the virtues of 
character and intellect. In order to be persuasive, a speaker must know how, in the speech, to present oneself as a trustworthy person with good judgment" (Beabout, 2013, 161).

This passage also raises an intriguing issue: proofs from character "must come about in the course of the speech, not from the speaker's being believed in advance to be of a certain character". There's quite a lot to be said about this. Firstly, there seems to be some tension with the concern with the speaker's reputation that we saw exhibited in Topics VIII. Perhaps this should not be surprising: as Janja Žmavc points out, Aristotle is also at odds with an earlier conception of ethos, sometimes referred to as $\varepsilon \pi \pi \varepsilon i x \varepsilon 1 \alpha$, as revealing an already established character (Žmavc, 2012, 184). This suggests that Aristotle departed in the Rhetoric from a traditional view he had implicitly endorsed in earlier work. (More tentatively, an analogy might be drawn between the temporally united conception of ethos in the Rhetoric and the unities of time and place proposed in the Poetics (Butcher. 1951, 1451a32).) Some modern authors explicitly deploy both conceptions of ethos. For example, Ruth Amossy: "the pragmatists' ethos, descended from Aristotle, is constructed within verbal interaction and is purely internal to discourse; the sociologists' ethos, on the other hand, is inscribed in a symbolic exchange governed by social mechanisms and external institutional positions ... however, these two approaches can be complementary rather than conflictual" (Amossy, 2001, 5).

Aristotle's exclusion of prior ethos seems a departure from some (tacit) assumptions in VTA, but maybe a valuable one. One immediate argument in favour of a no track-record approach is that track record requires keeping track! That is, it would simplify the process of character-based argument evaluation if only immediately available character aspects need be taken into account. Moreover, as we saw above, VTA must reject the twentieth-century textbook tradition that any reference to an arguer's character is automatically an ad hominem fallacy. But that's not to say that ad hominem arguments are never fallacious; rather, we now need to draw a line between the fallacious and non-fallacious cases. Aristotle's no track-record constraint may inspire a compromise proposal for the location of that line: reference your interlocutor's character all you please, but only as it is presented on this occasion-no harping back to previous encounters. However, this may be too restrictive: perhaps some legitimate ad hominem arguments would be ruled fallacious. Consider this example from Larry Powers: "I would strongly urge that you not listen to him. You know in advance that his argument is going to sound extremely convincing and compelling. His arguments always sound extremely convincing and compelling, quite independently of the truth or falsity of what he is arguing for" (Powers, 1998, emphases added). Powers defends the extreme position that no ad hominem arguments are fallacious, but one need not endorse that position to see that track record might be relevant to the determination of whether an ad hominem argument is legitimate.

Furthermore, a no track-record constraint may raise difficulties for the definition of argument. Communication theorists speak of "serial arguments": arguments that basically go on forever, like a couple who have been arguing about whose turn it is to do the washing up for forty years (Trapp and Hoff. 1985). There are many examples of such interminable arguments: the same participants engaging each other on the same issues over a long period, often with the same 
manoeuvres. If aspects of a speaker's character revealed in a serial argument are fair game throughout that argument, then track record seems to be back. Indeed, one serial argument might outlast several regular arguments; why should track record be admissible in the former but not the (more temporally united) latter? Indeed, the VTA-adjacent argumentation theorist Michael Gilbert has explicitly endorsed a track-record account of ethos: "An individual's ethotic rating [ER] comes first and most assuredly from previous interactions. Even when encountering someone for the first time the associations they carry, the context they bear, and the situation in which that encounter ensues all form a basis for at least a preliminary ER. Who introduced you, the purpose of the meeting, it's importance to you, the initial power standings of those involved, all serve to create an initial tentative ER" (Gilbert, 2015, 468). On balance, this seems the best way forward for a treatment of ethos in VTA.

2.3. Rhetoric II. Everything in the above passage from I.2 is consistent with an account of character as veridical. That is, it could be construed as assuming that the audience's perception of the speaker's character is always an accurate one. Less so the next passage, from II.1, which displays a greater emphasis on audience perception of character as something potentially distinct from the speaker's actual character:

But since the objective of rhetoric is judgement (for men give judgement on political issues and a court case is a judgement), we must have regard not only to the speech being demonstrative and persuasive, but also to establishing the speaker himself as of a certain type and bringing the giver of judgement into a certain condition. For this makes a great difference as regards proof, especially in deliberative oratory, but also in court cases-this appearance of the speaker as to be of a certain kind and his making the audience suppose that he is disposed in a certain way towards them, and in addition the condition that they are disposed in a certain way to him. Now the appearance of the speaker to have a certain character is more useful for political oratory, and the given disposition of the audience for the courts. For things do not seem the same to those who love and those who hate, nor to those who are angry and those who are calm, but either altogether different or different in magnitude. For to the friend the man about whom he is giving judgement seems either to have committed no offence or a minor one, while for the enemy it is the opposite. And to the man who is enthusiastic and optimistic, if what is to come is to be pleasant, it seems to be both likely to come about and likely to be good, while to the indifferent or depressed man it seems the opposite.

There are three causes of the speakers themselves being persuasive; for that is the number of the sources of proof other than

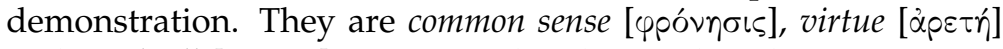

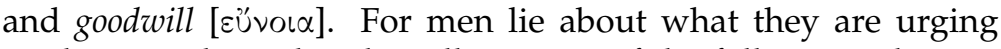
or claiming through either all or some of the following: they either have the wrong opinions through stupidity, or, while having the correct opinions through perversity they fail to say what they 
think; or they have common sense and integrity but are not welldisposed, whence they might not give the best advice, though they know it; and there are no other causes besides. So it must be that the man who is thought to have all of our first list is persuasive to the audience. Now the means of appearing to have common sense and integrity can be drawn from the distinctions we have given in connection with the virtues. For from the same points one might make both oneself and another seem to be of this kind. But about goodwill and friendship we must speak in the discussion of the emotions. (Aristotle, 1991. 1377b-1378a)

As Antoine Braet observes, the Rhetoric is "a nearly totally descriptive treatise of the means of persuasion" (Braet, 1992, 316). As such, it need not concern itself with whether an appearance of virtue may be misleading. But this turn to the audience perception of character raises a problem for VTA when understood as making evaluative claims. Even if there was no more to VTA than an exhortation to argue more virtuously, then recognizing the vices of our interlocutors would still seem a prerequisite. Aristotle's solution to this conundrum would be that the phronimos would not be fooled by a mere appearance of virtue: "it is generally accepted that the good man's view is the true one" (Aristotle, 1976, 1176a). (For a challenge to this aspect of the phronimos, see Baumtrog 2016)

The main attraction for VTA in this passage is that Aristotle introduces a threefold analysis of the role of character in argument: "common sense [ipóvn-

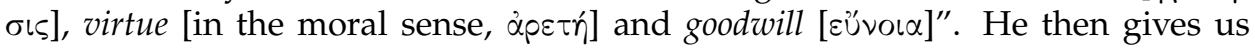
the flip side of this, the failure modes of these three causes: stupidity, a fail-

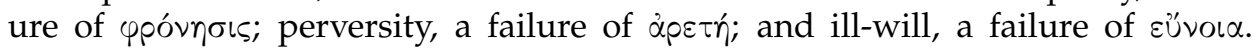
For William Fortenbaugh, Aristotle's use of this threefold account acknowledges established Greek practice: the division is "a tradition that goes back as far as Homer" (Fortenbaugh, 1992, 216). As such, he suggests that ypóvnoıs in particular should be read in its everyday sense here, "wisdom" generally construed, rather than as a term of art in Aristotle's ethical theory (Fortenbaugh. 1992, 220). If nothing else, this explains how anyone could have ypóvnols and apetń but lack

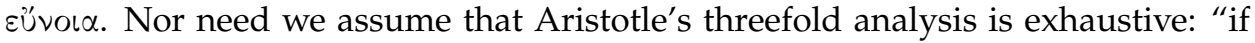
ethotic argument is sometimes justified in nondeliberative contexts, then some other aspects of $\tilde{\eta} \theta 0 \varsigma$, above and beyond the three mentioned by Aristotle, some more intellectual ones for example, will be of importance" (Brinton, 1986, 255). Aristotle also acknowledges in this passage the distorting potential of friendship, a correlate of $\varepsilon u ̈ v o l \alpha$; later passages which discuss character suggest the speaker may be most persuasive by reflecting back the audience's character, for better or for worse, "since all men accept speeches directed at their own age and their kind" (Aristotle, 1991. 1390a). One remedy which VTA might adopt to this issue would be to constrain $\alpha \rho \varepsilon \tau \dot{n}$ and عüvol $\alpha$ to their argumentational aspects.

VTA can productively reflect on all three of the components of character Aristotle identifies. I will pay particular attention to ypóvnoıs in the next section; but

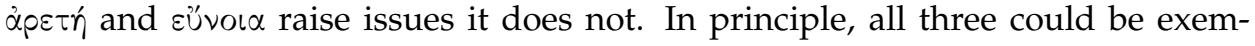
plified by the arguer or directly argued for, although in each case "one can better suggest ethos than prove it because attempting to prove ethos would produce doubt about the ethos!" (Braet, 1992, 312). Even so, the arguer may successfully persuade an audience by exemplifying aspects of $\dot{\alpha} \varepsilon \varepsilon \tau \dot{\eta}$ and $\varepsilon u^{\prime} v o \iota \alpha$ that are strictly 
irrelevant to the argument. Goodwill is a neglected feature of argument in both ancient and modern sources; one ambition for VTA should be to remedy this

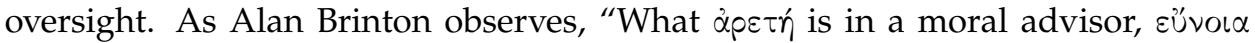
is in a prudential advisor" (Brinton, 1986, $254 \mathrm{f}$.). In his apparently independent account of ethos, mentioned above, Gilbert also proposes a threefold analysis, in terms of knowledgeability, trustworthiness and likability (Gilbert. 2016, 275). Each of these components is at least loosely analogous to one of the three Aristotelian components: likability is closed allied to goodwill, trustworthiness is a (moral) virtue, and knowledgeability is at least a component of common sense.

\section{IS THE PHRONIMOS AN IDEAL ARGUER?}

Whether or not the phronesis of the Rhetoric is identical to that of the Nicomachean Ethics, it is to phronesis in the latter, stronger sense that I turn in this section. In addition to his well-known roll-call of ethical virtues and their corresponding vices, Aristotle also identifies intellectual virtues: art or technical skill

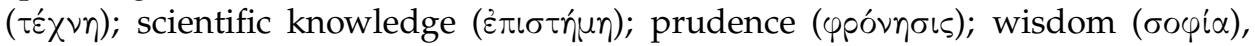

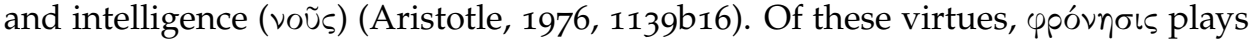
the most central role in this project, since the role which Aristotle assigns to the phronimos, the person who exemplifies phronesis, most directly connects to the twenty-first century project of VTA. I think you can make a plausible case that the phronimos is the exemplar of ideal argumentation. In fact, a plausible case has already been made, independently of VTA, by Lois Self and Amélie Rorty: "There are important theoretical and practical relationships between rhetoric and phronesis and it is the man of practical wisdom who has both the capacity and incentive to be an ideal practitioner of the Aristotelian art of rhetoric" (Self., 1979. 143); "In short, a brilliant, successful Persuader need not be a phronimos, but a phronimos must-among other things—rightly as well as successfully exercise the skills of a talented Persuader" (Rorty, 2011, 733).

They make essentially the same point: that all true phronimoi must be ideal arguers, but not vice versa: "the Persuader is not, qua rhetorician, a virtuous phronimos" but "it seems that the phronimos must have the abilities and skills of the best of Persuaders" (Rorty, 2011, 721). You could master the skills of the Rhetoric, learn the tricks, without exemplifying the virtue of phronesis. But that wouldn't make you an ideal arguer in the full sense; you might have great technical fluency and sophistication, but you would fall short of being an ideal arguer because you would be, potentially at least, an unprincipled rogue! "A Persuader can successfully craft an astute and even insightful legal defense for an unjust cause, but he does not qualify as a person of practical wisdom unless his desires and ends are genuinely good" (Rorty, 2011. 732). So the model to which we ought really to aspire is someone who knows when to use these skills appropriately. It is that broader, more well-rounded figure of the ideal arguer that we are trying to advocate for in VTA.

It is an important observation for VTA that there can be more people involved in an argument than just proponent and respondent; there can also be an audience, an arbiter, and other interested parties (Cohen, 2013. 480). If we accept that the ideal arguer should be a phronimos, where does that leave the other parties? This question has given rise to a conflict in the interpretation of Aristotle's work. For Susan Allard-Nelson, "An orator, if confronted by a phronimos, 
could only 'persuade' her to do precisely what she would have done, under the same conditions, anyway. The art of rhetoric, in order to be successful and to have a meaningful product, is dependent upon an audience composed mainly of stereotypes (i.e., the average person) and not of the ideal (i.e., the phronimos)" (Allard-Nelson, 2001, 258); whereas for Arash Abizadeh, "ethical rhetoric appears to require that phronêsis obtain not just in the rhetorician but additionally in the audience" (Abizadeh, 2002, 278). On Abizadeh's account, Aristotle requires the audience to be phronimoi; on Allard-Nelson's he requires that they not be. Although Abizadeh does not directly address Allard-Nelson's work, a resolution to the apparent inconsistency may be inferred from his account. He proposes that "the structural constitution of the art of rhetoric produces an internally generated propensity to induce judgments consistent with the outcomes of phronetic deliberation" (ibid.). Rhetoric thereby "enable[s] political institutions to reach correct outcomes despite the ethical shortcomings of the polity's members" (ibid.). In effect, this envisages an epiphenomenal phronimos, distributed over the multiple participants in a well-conducted dialogue. Hence the paradox is resolved: the audience has phronesis collectively, but lacks it distributively.

For Aristotle, phronesis is primarily concerned with deliberation, deciding upon the right course of action. VTA have a broader concern of argumentation in general, so any special role for phronesis in VTA would require a wider construal. Such a move is at least consistent with similar steps taken by some virtue epistemologists: "we ought to consider the virtue of phronesis, or practical wisdom, as a higher-order virtue that governs the entire range of moral and intellectual virtues" (Zagzebski, 1996, 229). There is an even broader implication: this privileged role for phronesis lends a privileged role to VTA too, making VTA necessary for a wide range of other projects. If to properly exemplify phronesis you need to be an ideal arguer, then VTA will be central to the virtue theory of anything. In order to properly exemplify the ethical virtues, or the epistemic virtues, or the virtues specific to any other practice, you would first need to be an ideal arguer. So there is potential here for an ambitious role for VTA as the capstone of virtue theories, a common point that they all need to share; that what the true virtue theory needs to have is an account of arguing in a way that is conducive to human flourishing (for further discussion, see Aberdein, 2020).

\section{REFERENCES}

Aberdein, Andrew. 2010. Virtue in argument. Argumentation 24(2): 165-179.

Aberdein, Andrew. 2014. In defence of virtue: The legitimacy of agent-based argument appraisal. Informal Logic 34(1): 77-93.

Aberdein, Andrew. 2016. The vices of argument. Topoi 35(2): 413-422.

Aberdein, Andrew. 2018. Inference and virtue. In Argumentation and Inference: Proceedings of the 2nd European Conference on Argumentation, Fribourg 2017, eds. Steve Oswald and Didier Maillat, vol. 2, 1-9. London: College Publications.

Aberdein, Andrew. 2019. Courageous arguments and deep disagreements. Topoi Forthcoming.

Aberdein, Andrew. 2020. Eudaimonistic argumentation. In From Argument Schemes to Argumentative Relations in the Wild: A Variety of Contributions to Argumentation Theory, eds. Frans H. van Eemeren and Bart Garssen, 97-106. Cham: Springer. 
Abizadeh, Arash. 2002. The passions of the wise: Phronêsis, rhetoric, and Aristotle's passionate practical deliberation. The Review of Metaphysics 56(2): 267-296. Aikin, Scott F. and Mark Anderson. 2006. Argumentative norms in Republic I. Philosophy in the Contemporary World 13(2): 18-23.

Allard-Nelson, Susan K. 2001. Virtue in Aristotle's Rhetoric: A metaphysical and ethical capacity. Philosophy and Rhetoric 34(3): 245-259.

Amossy, Ruth. 2001. Ethos at the crossroads of disciplines: Rhetoric, pragmatics, sociology. Poetics Today 22(1): 1-23.

Aristotle. 1976. Ethics. London: Penguin. Translated by J. A. K. Thomson.

Aristotle. 1984. Topics. In The Complete Works of Aristotle, ed. Jonathan Barnes, vol. I, 167-277. Princeton, NJ: Princeton University Press. Translated by W. A. Pickard-Cambridge.

Aristotle. 1991. The Art of Rhetoric. London: Penguin. Translated by H. LawsonTancred.

Axtell, Guy. 1997. Recent work in virtue epistemology. American Philosophical Quarterly 34(1): 1-27.

Bailin, Sharon and Harvey Siegel. 2003. Critical thinking. In The Blackwell Guide to the Philosophy of Education, eds. Nigel Blake, Paul Smeyers, Richard Smith, and Paul Standish, 181-193. Oxford: Blackwell.

Battaly, Heather. 2008. Virtue epistemology. Philosophy Compass 3(4): 639-663.

Baumtrog, Michael D. 2016. The willingness to be rationally persuaded. In Argumentation, Objectivity and Bias: Proceedings of the 11th International Conference of the Ontario Society for the Study of Argumentation (OSSA), May 18-21, 2016, eds. Patrick Bondy and Laura Benacquista. Windsor, ON: OSSA.

Beabout, Gregory R. 2013. What contemporary virtue ethics might learn from Aristotle's Rhetoric. Proceedings of the American Catholic Philosophical Association 87: 155-166.

Blair, J. Anthony and Ralph H. Johnson. 2011. Conductive Argument: An Overlooked Type of Defeasible Reasoning. London: College Publications.

Braet, Antoine C. 1992. Ethos, pathos and logos in Aristotle's Rhetoric: A reexamination. Argumentation 6(3): 307-320.

Brinton, Alan. 1986. Ëthotic argument. History of Philosophy Quarterly 3(3): 245258.

Butcher, S. H. 1951. Aristotle's Theory of Poetry and Fine Art, with a Critical Text and Translation of the Poetics. New York, NY: Dover.

Callard, Agnes. 2019. The devil's advocate's advocate. The Point Magazine Online at https://thepointmag.com/2019/examined-life/ the-devils-advocates-advocate-agnes-callard.

Campolo, Chris. 2019. On staying in character: Virtue and the possibility of deep disagreement. Topoi 38(4): 719-723.

Cohen, Daniel H. 2005. Arguments that backfire. In The Uses of Argument, eds. David Hitchcock and Daniel Farr, 58-65. Hamilton, ON: OSSA.

Cohen, Daniel H. 2009. Keeping an open mind and having a sense of proportion as virtues in argumentation. Cogency 1(2): 49-64.

Cohen, Daniel H. 2013. Virtue, in context. Informal Logic 33(4): 471-485.

Cohen, Daniel H. and Katharina Stevens. 2019. Why devil's advocates are the angels of argumentation. Presented at 3rd European Conference on Argumentation, Groningen, The Netherlands. 
Dutilh Novaes, Catarina. 2015. A dialogical, multi-agent account of the normativity of logic. Dialectica 69(4): 587-609.

Ennis, Robert H. 1996. Critical thinking dispositions: Their nature and assessability. Informal Logic 18(2-3): 165-182.

Facione, Peter A. 2000. The disposition toward critical thinking: Its character, measurement, and relationship to critical thinking skill. Informal Logic 20(1): 61-84.

Fortenbaugh, William W. 1992. Aristotle on persuasion through character. Rhetorica 10(3): 207-244.

Gilbert, Michael A. 2015. Rules is rules: Ethos and situational normativity. In Proceedings of ISSA 2014: Eighth Conference of the International Society for the Study of Argumentation, eds. Bart J. Garssen, David Godden, Gordon Mitchell, and A. Francisca Snoeck Henkemans, 467-474. Amsterdam: Sic Sat.

Gilbert, Michael A. 2016. Ethos, familiars and micro-cultures. In The Psychology of Argument: Cognitive Approaches to Argumentation and Persuasion, eds. Fabio Paglieri, Laura Bonelli, and Silvia Felletti, 275-285. London: College Publications.

Paglieri, Fabio. 2015. Bogency and goodacies: On argument quality in virtue argumentation theory. Informal Logic 35(1): 65-87.

Powers, Lawrence H. 1998. Ad hominem arguments. In Argumentation and Rhetoric, eds. H. V. Hansen, C. W. Tindale, and A. V. Colman. Newport News, VA: Vale.

Rapp, Christof and Tim Wagner. 2013. On some Aristotelian sources of modern argumentation theory. Argumentation 27: 7-30.

Rorty, Amélie. 2011. Aristotle on the virtues of rhetoric. The Review of Metaphysics 64(4): 715-733.

Rubinelli, Sara. 2009. Ars Topica: The Classical Technique of Constructing Arguments from Aristotle to Cicero. Dordrecht: Springer.

Santas, Gerasimos X. 1997. Does Aristotle have a virtue ethics? In Virtue Ethics: A Critical Reader, ed. D. Statman, 260-285. Washington, DC: Georgetown University Press.

Self, Lois S. 1979. Rhetoric and phronesis: The Aristotelian ideal. Philosophy and Rhetoric 12(2): 130-145.

Smith, Robin. 1997. Aristotle. Topics. Books I and VIII. Oxford: Oxford University Press.

Sosa, Ernest. 1991. Knowledge in Perspective: Selected Essays in Epistemology. Cambridge: Cambridge University Press.

Trapp, Robert and Nancy Hoff. 1985. A model of serial argument in interpersonal relationships. Journal of the American Forensic Association 22: 1-11.

Zagzebski, Linda. 1996. Virtues of the Mind. Cambridge: Cambridge University Press.

Žmavc, Janja. 2012. The ethos of classical rhetoric: From epieikeia to auctoritas. In Topical Themes in Argumentation Theory, eds. Frans H. van Eemeren and Bart Garssen, 181-191. Dordrecht: Springer. 